\title{
Knowledge of medical students about perioperative nutritional care in Bahia, Brazil: a transversal study
}

\author{
Conhecimento de estudantes de medicina sobre \\ cuidados nutricionais perioperatórios na Bahia, \\ Brasil: estudo transversal
}

\section{Rodrigo Fernandes Weyll Pimentel ${ }^{1}$ (i) Leonardo Castro Dantas Macêdo 2 (1) Sérgio Diniz Gonçalves Queiroz Filho 3 (1)}

\section{Pedro Carlos Muniz de Figueiredo 4 (1) Magno Conceição das Merces 5 (1)}

${ }^{1}$ Corresponding author. Complexo Hospitalar Universitário Professor Edgard Santos (Salvador). Bahia, Brazil. rodrigo.pimentel@ebserh.gov.br 2,3Universidade Salvador (Salvador). Bahia, Brasil. leonardocdm83@gmail.com, sergio.filho98@gmail.com ${ }^{4}$ Complexo Hospitalar Universitário Professor Edgard Santos (Salvador). Bahia, Brazil. pedro.figueiredo@ebserh.gov.br 5Universidade do Estado da Bahia (Salvador). Bahia, Brazil.mmerces@uneb.br

\begin{abstract}
OBJECTIVE: Evaluate the medical students' knowledge about perioperative nutritional care. These students are from public and private academic institutions in the state of Bahia, Brazil. METHODS: This is a cross-sectional study to analyze medical students based on an online instrument regarding topics related to perioperative care. For data analysis, absolute and relative frequencies were calculated for categorical variables, and mean and standard deviation were calculated for continuous variables. Fisher's Exact Test and G Test were used to analyze the association. RESULTS: 209 responses were obtained. Regarding the learning on nutritional preparation of the patient submitted to a surgery, 25 (64.9\%) students of public institutions and $90(52.3 \%)$ students of private ones reported not knowing or not having been exposed to such knowledge. Regarding the importance of addressing topics related to nutritional therapy (NT), 37 (100\%) students from public institutions and 168 (97.7\%) from private ones recognize the importance of spreading this knowledge. Unnecessary absolute preoperative fasting, shortening techniques of fasting and bronchoaspiration prevention, and reintroduction time of a diet in the postoperative period are unknown to most of the population studied. CONCLUSION: Most students included in this study do not have satisfactory knowledge in NT and preparing the surgical patient.
\end{abstract}

KEYWORDS: Medical Students. Nutritional Therapy. Perioperative Care. Public Health.
RESUMO | OBJETIVO: Avaliar o conhecimento dos estudantes de Medicina de instituições públicas e privadas do estado da Bahia, Brasil sobre cuidados nutricionais perioperatórios. MÉTODOS: Trata-se de um estudo transversal que analisou estudantes de Medicina através de um instrumento online sobre temas relativos aos cuidados perioperatórios. Para análise dos dados, foram calculadas as frequências absoluta e relativa para as variáveis categóricas, e a média e o desvio padrão para as contínuas. Para a análise da associação, foi utilizado o teste Exato de Fisher e o teste G. RESULTADOS: Foram obtidas 209 respostas. Com relação ao aprendizado do preparo nutricional do paciente cirúrgico, 25 (64,9\%) dos estudantes de escolas públicas e 90 (52,3\%) das privadas relataram não saber ou não terem sido expostos. Sobre a importância de se abordar temas relacionados à terapia nutricional (TN), 37 (100\%) acadêmicos de instituições públicas e 168 (97,7\%) das privadas reconhecem a importância da difusão deste conhecimento. Não necessidade de jejum absoluto pré-operatório, técnicas de abreviação de jejum e prevenção de broncoaspiração e o momento de reintrodução da dieta no pós-operatório são desconhecidas da maioria da população estudada. CONCLUSÃO: A maioria dos acadêmicos incluídos neste estudo não possuem conhecimentos satisfatórios em TN e no preparo do paciente cirúrgico.

PALAVRAS-CHAVE: Estudantes de Medicina. Terapia Nutricional. Cuidados Perioperatórios. Saúde Pública. 


\section{Introduction}

According to DATASUS, in 2018, 4,823,517 surgical procedures occurred in Brazil, with 3.6 average days of hospitalization per person, generating an average cost of $\mathrm{R} \$ 1,613.47$ per patient and 76,442 deaths. ${ }^{1}$ These data demonstrate how surgeries affects public health and highlight the importance of understanding more about the factors that interfere in the process of surgical patient care to reduce hospitalization time, mortality, and government costs. $\stackrel{\text { ? }}{\text { ? }}$

Among the factors that interfere in the success of surgery, the patient's nutritional status stands out. ${ }^{3}$ Several studies have shown that malnourished patients have a higher risk of postoperative complications and mortality. ${ }^{-}$The Brazilian hospital nutritional assessment survey (IBRANUTRI) identified that almost $50 \%$ of patients admitted to the Public Health System of Brazil (SUS) have some degree of malnutrition, ranging from moderate to severe. ${ }^{4}$ Nutritional Therapy (NT) arises in this context as an alternative for preventing hospital malnutrition. The main objectives of NT are the following: (I) prevent and treat malnutrition, (II) prepare the patient for the surgical procedure, (III) improve the immune and scar response, (IV) modulate the organic response to surgical treatment, $(\mathrm{V})$ reduce hospital stay time, (VI) reduce mortality and, consequently, (VII) reduce hospital costs. $\frac{5}{}$

Several themes are developed during the six years of academic training of the Brazilian physician from the basic cycle, clinical cycle, and internship. Among the topics necessary in this training, the NT is approached superficially, sometimes insufficient in the medical student qualification.. As a result, there is a need for a better preparation of future physicians to identify nutritional risks in monitoring hospitalized patients, especially those in chronic conditions. .6 Nutritional control and analysis are fundamental for treating hospitalized patients, especially in the postoperative period. $\underline{6}$
Many barriers exist for efficient NT education among medical students. These difficulties include limited contact with patients, unknown importance in some treatments, low administrative support, and a limited number of professionals updated on the nutritional area.. Furthermore, when nutritional content is introduced in medical colleges and universities, this knowledge is based on biochemical foundations rather than a clinical nutritional application, which leads to students being inadequately prepared for practical clinical tasks. ${ }^{\underline{7}}$ Therefore, it is extremely important to integrate nutritional approaches into different curricular components involving various systems, organs, and pathologies. In addition, it is necessary to take advantage of opportunities to experience the clinic interventions. ${ }^{?}$

Given the understanding of the nutrition importance in front of surgical patients, as well as gaps in scientific evidence about the knowledge of medical students about NT, this study aims to evaluate the knowledge of medical students from public and private institutions in the state of Bahia, Brazil, about perioperative nutritional care.

\section{Methods}

This is a cross-sectional study based on identified data. We included medical students studying from the 1 st to the 12th semester, older than 18 years, who agreed to sign the Free and Informed Consent Form (FICF). The students who had self-informed previously attended other degrees in the health area were excluded. Participants were recruited through messages on social networks and/or messaging applications, in which invitations were triggered in groups known to have medical students or to students' profiles. The study subjects were encouraged at the end of the questionnaire to invite other colleagues to participate in the research (snowball sampling technique). Recruitment was made between May and August 2020. 
An instrument with multiple-choice questions divided into two parts was applied, made electronically available on the Microsoft Forms ${ }^{\circledR}$ platform. The first part of the questionnaire deals with participants' data, namely: age, gender, graduation year in progress, whether they were enrolled in a public or private university. The second part consisted of questions related to the participant's familiarity with the topics on perioperative care, including test questions asked to assess their knowledge and whether these topics were addressed or not throughout their training.

For analysis of categorical variables, absolute frequency (AF) and relative frequency (RF) were calculated. For continuous variables, mean and standard deviation were calculated. The statistical analysis was developed using Microsoft Excel ${ }^{\circledR}$ software for Windows ${ }^{\circledR}$, version 2019. Fisher's Exact Test was used to analyze the association between categorical variables (cycles of public or private institutions). For the comparison of intercycles in the same type of the university, the $G$ test was used. A value of $p<0.05$ was considered statistically significant.

At all stages of the research, Resolution 466/2012 concerning research involving human beings was respected. All participants agreed to sign the TCLE in an electronic version. This research was registered with the Research Ethics Committee of the State University of Bahia (UNEB) under CAAE 30921820.3.0000.0057 and approved by Opinion No. 4.100.095.

\section{Results}

A total of 268 responses to the questionnaire were obtained, and 03 participants were excluded. They did not accept the ICT and 56 because they had already attended another degree in the health area. Thus, a total of 209 participants were analyzed, of which 53 (25.4\%) were in the basic cycle (1st and second years), 129 (61.7\%) were in the clinical cycle (3rd and fourth years), and 27 (12.9\%) were in the internship (5th and sixth years). As for the type of University, 172 (82.3\%) participants studied medicine at a private university while $37(17.7 \%)$ attended a public university. Table 01 presents the sociodemographic profile of the participants.

Table 1. Characteristics of study participants, Bahia, Brazil, 2020

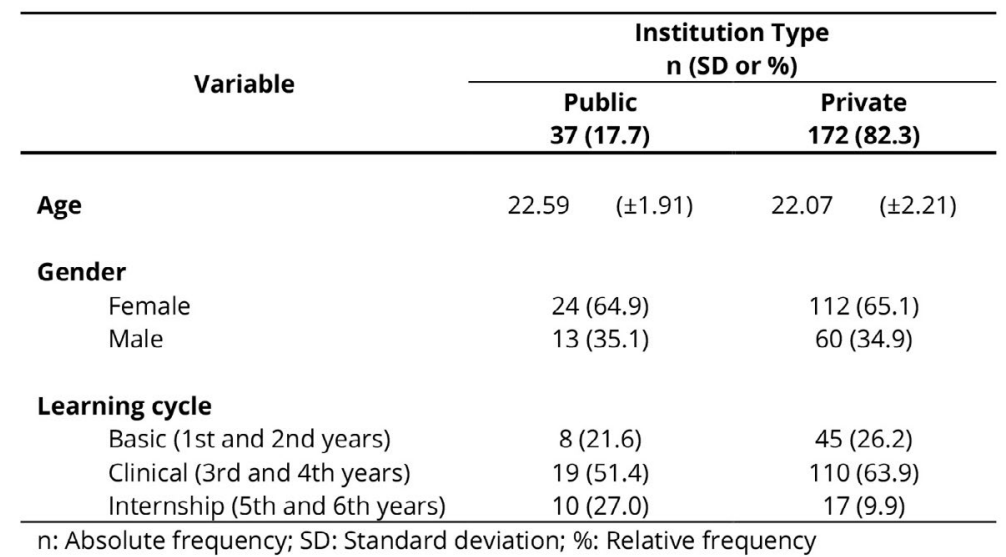


Regarding the curricular content of the medical courses, 21 (56.8\%) students from public universities and $111(64.5 \%)$ from private universities said they had some knowledge about NT. When stratified by learning cycle, it is found that most students (69.8\%) report not knowing or did not have some learning related to NT during the basic cycle. There was a statistically significant difference when comparing the knowledge about NT and intercycles of public or private institutions. When asked specifically about the learning on nutritional preparation of the surgical patient, the majority of students - 25 (64.9\%) from public schools and 90 (52.3\%) from private ones reported not knowing or not having been exposed to these kinds of learning. There was also a statistically significant difference in the knowledge on this topic and intercycles of public or private institutions.

Regarding nutritional risk, 26 (70.3\%) students from public universities and 126 (73.3\%) from private ones reported knowing about this topic. When asked if the surgical patient has any nutritional risk, 31 (83.8\%) students from public institutions and 154 (89.5\%) from private ones identified the possibility of this risk. Considering the knowledge about nutritional risk screening tools, 29 (78.4\%) students in public universities and 106 (61.6\%) of private ones reported not knowing any of these tools. There was a statistically significant difference in comparing these knowledge topics and intercycles of learning from private universities.

Finally, regarding the importance of addressing issues related to NT during the medical course, the vast majority of students, whether from public or private institutions $37(100 \%)$ and 168 (97.7\%), respectively, recognize how important it is to disseminate this knowledge in their academic training. The table 2 summarizes the information related to these data.
It was observed that $26(70.3 \%)$ students from public institutions and 104 (60.5\%) from private ones did not know about concepts inherent to the unnecessary absolute fasting of surgical patients for all types of food. The lack of knowledge about fasting abbreviation techniques of these patients was reported by 19 (51.4\%) of students from public institutions and 79 (45.9\%) from private institutions. There was also a statistically significant difference between the knowledge of fasting abbreviation demonstrated by the students of the clinical cycle of private educational institutions when compared to those of public education.

The erroneous association of maintaining absolute fasting with prevention of bronchoaspiration was reported by 23 participants (62.2\%) from public institutions, the equivalent to what was reported by 96 students from private schools (55.8\%). The concepts of nutritional preparation of the surgical patient seem to have been appropriate by most students from both types of medical schools, public and private (32 (86.5\%) and $134(77.9 \%)$, respectively). The same appropriation is reflected in the understanding of immunonutrition (public: 19 (51.4\%) and private: $92(53.5 \%))$. Most students also do not know the best moment to reintroduce the use of the gastrointestinal tract in the postoperative period, referring to the need for the presence of water-based noise to perform this action: 22 (59.5\%) students from public schools and 102 (59.3\%) from private ones.

For all topics related to knowledge about perioperative care in surgical patients, there was a statistically significant difference between the cycles in private institutions.

The table 3 summarizes the knowledge about some points of perioperative care spent on surgical patients. 
Table 2. Information related to knowledge about NT, nutritional risk and importance of the topic for the medical course, Bahia, Brazil, 2020

\begin{tabular}{|c|c|c|c|c|c|c|c|c|c|c|}
\hline \multirow[t]{2}{*}{ Knowledge Topic } & \multicolumn{4}{|c|}{$\begin{array}{l}\text { Public Institution } \\
\mathrm{n}(\%)\end{array}$} & \multirow[t]{2}{*}{ P-value } & \multicolumn{4}{|c|}{$\begin{array}{c}\text { Private Institution } \\
\mathrm{n}(\%)\end{array}$} & \multirow[t]{2}{*}{ P-value } \\
\hline & Basic & Clinical & Internship & Total & & Basic & Clinical & Internship & Total & \\
\hline \multicolumn{11}{|l|}{ Nutritional Therapy } \\
\hline Yes & $1(12.5)$ & $11(57.9)$ & $9(90.0)$ & $21(56.8)$ & \multirow{2}{*}{ ** } & $15(33.3)$ & $83(75.5)$ & $13(76.5)$ & $111(64.5)$ & \multirow{2}{*}{$* *$} \\
\hline No / I don't know & $7(87.5)$ & $8(42.1)$ & $1(10.0)$ & $16(43.2)$ & & $30(66.7)$ & $27(24.5)$ & $4(23.5)$ & $61(35.5)$ & \\
\hline \multicolumn{11}{|l|}{ SP nutritional preparation } \\
\hline Yes & $0(0.0)$ & $8(42.1)$ & $5(50.0)$ & $13(35.1)$ & \multirow{2}{*}{$\star \star$} & $5(11.1)$ & $71(64.5)$ & $6(35.3)$ & $82(47.7)$ & \multirow{2}{*}{$* \star$} \\
\hline No / I don't know & $8(100)$ & $11(57.9)$ & $5(50.0)$ & $24(64.9)$ & & $40(88.9)$ & $39(35.5)$ & $11(64.7)$ & $90(52.3)$ & \\
\hline \multicolumn{11}{|l|}{ Nutritional Risk } \\
\hline Yes & $3(37.5)$ & $14(73.7)$ & $9(90.0)$ & $26(70.3)$ & \multirow{3}{*}{$* * *$} & $25(55.6)$ & $88(80.0)$ & $13(76.5)$ & $126(73.3)$ & \multirow{2}{*}{$* *$} \\
\hline No & $5(62.5)$ & $5(26.3)$ & $1(10.0)$ & $11(29.7)$ & & $20(44.4)$ & $22(20.0)$ & $4(23.5)$ & $46(26.7)$ & \\
\hline \multicolumn{10}{|l|}{ SP nutritional risk } & \\
\hline Yes & $5(62.5)$ & $16(84.2)$ & $10(100)$ & $31(83.8)$ & \multirow{2}{*}{$* * *$} & $34(75.6)$ & $104(94.5)$ & $16(94.1)$ & $154(89.5)$ & \multirow{2}{*}{$* *$} \\
\hline No & $3(37.5)$ & $3(15.8)$ & $0(0.0)$ & $6(16.2)$ & & $11(24.4)$ & $6(5.5)$ & $1(5.9)$ & $18(10.5)$ & \\
\hline \multicolumn{11}{|l|}{ NT tools } \\
\hline Yes & $1(12.5)$ & $4(21.1)$ & $3(30.0)$ & $8(21.6)$ & \multirow{3}{*}{$* * *$} & $1(2.2)$ & $61(55.5)$ & $4(23.5)$ & $66(38.4)$ & \multirow{2}{*}{$* *$} \\
\hline No & $7(87.5)$ & $15(78.9)^{*}$ & $7(70.0)$ & $29(78.4)$ & & $44(97.8)$ & $49(44.5)^{*}$ & $13(76.5)$ & $106(61.6)$ & \\
\hline \multicolumn{10}{|l|}{ Importance of teaching NT } & \\
\hline Yes & $8(100)$ & $19(100)$ & $10(100)$ & $37(100)$ & \multirow{2}{*}{$* * *$} & $45(100)$ & $106(96.4)$ & $17(100)$ & $168(97.7)$ & \multirow{2}{*}{$* * *$} \\
\hline No & $0(0.0)$ & $0(0.0)$ & $0(0.0)$ & $0(0.0)$ & & $0(0.0)$ & $4(3.6)$ & $0(0.0)$ & $4(2.3)$ & \\
\hline
\end{tabular}


Table 3. Information related to knowledge about some of the perioperative care in surgical patients, Bahia, Brazil, 2020

\begin{tabular}{|c|c|c|c|c|c|c|c|c|c|c|}
\hline \multirow[t]{2}{*}{ Knowledge Topic } & \multicolumn{4}{|c|}{$\begin{array}{c}\text { Public Institution } \\
\mathrm{n}(\%)\end{array}$} & \multirow[t]{2}{*}{ P-value } & \multicolumn{4}{|c|}{$\begin{array}{c}\text { Private Institution } \\
\mathrm{n}(\%)\end{array}$} & \multirow[t]{2}{*}{ P-value } \\
\hline & Basic & Clinical & Internship & Total & & Basic & Clinical & Internship & Total & \\
\hline \multicolumn{11}{|l|}{ Necessary fasting } \\
\hline With knowledge of the topic & $2(25.0)$ & $6(31.6)$ & $3(30.0)$ & $11(29.7)$ & \multirow{2}{*}{$* * *$} & $7(15.6)$ & $56(50.9)$ & $5(29.4)$ & $68(39.5)$ & \multirow{2}{*}{ ** } \\
\hline Without knowledge of the topic & $6(75.0)$ & $13(68.4)$ & $7(70.0)$ & $26(70.3)$ & & $38(84.4)$ & $54(49.1)$ & $12(70.6)$ & $104(60.5)$ & \\
\hline \multicolumn{11}{|l|}{ Abbreviation of fasting } \\
\hline With knowledge of the topic & $4(50.0)$ & $7(36.8)$ & $7(70.0)$ & $18(48.6)$ & \multirow{3}{*}{$* * *$} & $9(20.0)$ & $73(66.4)$ & $11(64.7)$ & $93(54.1)$ & \multirow{2}{*}{ ** } \\
\hline Without knowledge of the topic & $4(50.0)$ & $12(63.2)^{*}$ & $3(30.0)$ & $19(51.4)$ & & $36(80.0)$ & $37(33.6)^{*}$ & $6(35.3)$ & 79 (45.9) & \\
\hline \multicolumn{10}{|l|}{ Risk of bronchoaspiration } & \\
\hline With knowledge of the topic & $2(25.0)$ & $7(36.8)$ & $5(50.0)$ & $14(37.8)$ & \multirow{2}{*}{ 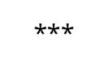 } & $5(11.1)$ & $64(58.2)$ & $7(41.2)$ & $76(44.2)$ & \multirow{2}{*}{ ** } \\
\hline Without knowledge of the topic & $6(75.0)$ & $12(63.2)$ & $5(50.0)$ & $23(62.2)$ & & $40(88.9)$ & $46(41.8)$ & $10(58.8)$ & $96(55.8)$ & \\
\hline \multicolumn{11}{|l|}{ Preoperative nutritional preparation } \\
\hline With knowledge of the topic & $7(87.5)$ & $17(89.5)$ & $8(80.0)$ & $32(86.5)$ & \multirow{3}{*}{$* \star *$} & $27(60.0)$ & $92(83.6)$ & $15(88.2)$ & $134(77.9)$ & \multirow{2}{*}{ ** } \\
\hline Without knowledge of the topic & $1(12.5)$ & $2(10.5)$ & $2(20.0)$ & $5(13.5)$ & & $18(40.0)$ & $18(16.4)$ & $2(11.8)$ & $38(22.1)$ & \\
\hline \multicolumn{10}{|l|}{ Indication of immunonutrition } & \\
\hline With knowledge of the topic & $5(62.5)$ & $8(42.1)$ & $6(60.0)$ & $19(51.4)$ & & $18(40.0)$ & $68(61.8)$ & $6(35.3)$ & $92(53.5)$ & \multirow{2}{*}{ ** } \\
\hline Without knowledge of the topic & $3(37.5)$ & $11(57.9)$ & $4(40.0)$ & $18(48.6)$ & & $27(60.0)$ & $42(38.2)$ & $11(64.7)$ & $80(46.5)$ & \\
\hline \multicolumn{11}{|l|}{ Food reintroduction in the PO } \\
\hline With knowledge of the topic & $2(25.0)$ & $7(36.8)$ & $6(60.0)$ & $15(40.5)$ & \multirow{2}{*}{$* * *$} & $10(22.2)$ & $51(46.4)$ & $9(52.9)$ & $70(40.7)$ & \multirow{2}{*}{$*$} \\
\hline Without knowledge of the topic & $6(75.0)$ & $12(63.2)$ & $4(40.0)$ & $22(59.5)$ & & $35(77.8)$ & $59(53.6)$ & $8(47.1)$ & $102(59.3)$ & \\
\hline
\end{tabular}


This study fills a gap of evidence on medical students' learning regarding the subjects related to surgical nutrition in Brazil. The inclusion and continuous evaluation of clinical nutrition education in the curricula of medical schools have been identified as one of the priorities by researchers dedicated to medical education. $\frac{89}{9}$ In addition to this fact, the importance of conducting this research is even more evident after presenting the results that point to the knowledge precariousness of medical students of Bahia universities regarding the perioperative NT.

Perioperative NT is relevant for the preparation of the surgical patient. The proper use of nutritional formulas can reduce the chances of infection by approximately $50 \%$, especially reducing the length of stay. 10 The present study showed that 16 (43.2\%) of public medical school students and 61 (35.5\%) of private schools did not know what NT was. On the other hand, $24(64.9 \%)$ of the public university participants and 90 (52.3\%) of the private university participants did not know the nutritional preparation of the surgical patient. When evaluated according to the academic cycle, $8(100 \%)$ of the public universities and 40 (88.9\%) of the private universities who attended the basic cycle did not respond correctly. Among the students of the internship cycle, there were 5 (50\%) and 11 (64.9\%) between public and private, respectively.

Although there is a clear improvement in the results among the students of the basic cycle compared to the internship students, it is necessary to take a more critical look at how the subject is approached in universities. This knowledge should be consolidated and mastered by students, especially those who are already in their last two years of the medical course and are closer to completing their academic training. This observation is even more based after $37(100 \%)$ of public institution students and 168 (97.7\%) of private institutions recognize the importance of teaching NT in the curricular matrix of the medical course.

Regarding the specific knowledge expressed in Table 3, one of the aspects to be highlighted is the topic related to preoperative fasting. Preoperative fasting should not be extended according to the project acceleration of Total Postoperative Recovery
(ACERTO). Instead, carbohydrate liquids could be offered up to two hours before the anesthetic act. 6 Despite this strong degree of recommendation, already evidenced in the literature fifteen years ago, $26(70.3 \%)$ students of a public institution and 104 (60.5\%) of private institutions are unaware of the nonneed for absolute fasting for surgical patients. This highlights the need for teachers and coordinators of medical courses to update their classes and curricula to pass on up-to-date information to students. The search for articles and students' engagement in the field of practice can help solidify the construction of this knowledge.

In addition to the lack of this knowledge in the preoperative setting, the majority of participants did not understand the postoperative nutritional approach, where 22 (59.5\%) of public university students and 102 (59.3\%) of private university students did not understand the appropriate time for food reintroduction in the operated patient. Such results could be associated with the fact that these concepts are not presented in a didactic pedagogical structure that facilitates the students' understanding, or there are difficulties on the part of the professors to approach the topic in the classroom. These difficulties often arise due to the reduced time spent teaching nutrition 10 , mainly due to the reduced workload compared to other existing curricular components in the medical course. Thus, according to Barros et al., there are other barriers to the integration of Clinical Nutrition into medical practice. Among the main obstacles cited by the physician are the lack of time (restricted consultation time) and the reduced medical preparation on the topic of Clinical Nutrition. 10

The reforms in the medical curriculum in Brazil and worldwide since 2001 have specified the profile of graduated physicians as generalist professionals. This allowed a review of the current state of nutrition knowledge teaching in medical schools and, thus, the possible expansion of this integration in this context. ${ }^{10}$ As a result, some proposals were created to encourage the inclusion of clinical knowledge of nutrition in the training of general practitioners. For example, there is the creation of a curricular guide to training physicians, overcoming the misconception that nutrition is not clinically relevant to an adequate medical education school; create innovative teaching tools..$^{11}$ 
It is necessary to point out some limitations of the present study, namely: (I) there was a high number of participants excluded from the research because they have already studied another health area, (II) because it is a cross-sectional study, it is not possible to infer causality, (III) the study was conducted in a virtual environment, limited to students who received questionnaire via e-mail and social network, which may confer a sampling bias.

Since no studies were addressing this subject in the literature, this work opens new perspectives for developing medical education in universities throughout the country, implementing a teaching plan that addresses a relevant surgical nutrition study for improving physicians' knowledge. Through these actions, it is expected to have a greater impact on the reduction of costs related to patients undergoing surgery, a decrease in the rates of post-surgical complications, as well as a shorter hospital stay time for these patients, consequently increasing the availability of beds and higher turnover of surgeries.

\section{Conclusion}

Medical students of Bahia who participated in the research do not have, to a large extent, satisfactory knowledge in NT and the preparation of the surgical patient. Nevertheless, private university students performed better than those of public universities, especially in the group of individuals in the clinical cycle, and may be related to the insertion of the topic in the curriculum matrix of that period.

Due to the scarce literature on the subject, there is an urgent need for new studies, especially at the national level, so that it is possible to map the situation better and, therefore, develop new methodologies to improve Nutrition Therapy teaching. Furthermore, such new methodologies may improve the academic training of all future physicians in the country.

\section{Authors' contribution}

Pimentel RFW, Macêdo LCD, Queiroz Filho SDG, Merces MC Figueiredo PMC participated in the conceptualization and methodology, data curation, validation, investigation, review, and final writing of the article.

\section{Competing interests}

No financial, legal, or political competing interests with third parties (government, commercial, private foundation, etc.) were disclosed for any aspect of the submitted work (including but not limited to grants, data monitoring board, study design, manuscript preparation, statistical analysis, etc.).

\section{References}

1. Ministério da Saúde (Brasil). Sistema de Informação Hopitalar [Internet]. 2019 [cited 2019 Aug 31]. Available from: http://sihd. datasus.gov.br/principal/index.php

2. Bozzetti F, Gianotti L, Braga M, Di Carlo V, Mariani L. Postoperative complications in gastrointestinal cancer patients: The joint role of the nutritional status and the nutritional support. Clin Nutr. 2007;26(6):698-709. https://doi.org/10.1016/j. clnu.2007.06.009

3. Waitzberg DL, Caiaffa WT, Correia MITD. Hospital malnutrition: The Brazilian national survey (IBRANUTRI): A study of 4000 patients. Nutrition. 2001;17(7-8):573-80. https://doi.org/10.1016/ s0899-9007(01)00573-1
4. van Bokhorst-de van Der Schueren MAE, van Leeuwen PAM, Sauerwein HP, Kuik DJ, Snow GB, Quak JJ. Assessment of malnutrition parameters in head and neck cancer and their relation to postoperative complications. Head Neck. 1997;19(5):419-25. https://doi.org/10.1002/(sici)1097- 0347(199708)19:5\%3C419::aid-hed9\%3E3.0.c0;2-2

5. Dannhauser A, Van Zyl JM, Nel CJ. Preoperative Nutritional Status And Prognostic Nutritional Index In Patients With Benign Disease Undergoing Abdominal Operations-Part I. J Am Coll Nutr. 1995;14(1):80-90. https://doi.org/10.1080/07315724.1995.1 $\underline{0718477}$

6. Aguilar-Nascimento JE, editor. ACERTO: Acelerando a recuperação total pós-operatória. Rio de Janeiro: Rubio; 2016. 
7. Boog MCF. Difficulties found by physicians and nurses in approaching eating problems. Rev Nutr. 1999;12(3):261-72. https://doi.org/10.1590/S1415-52731999000300006

8. Adams KM, Kohlmeier M, Zeisel SH. Nutrition education in U.S. medical schools: Latest update of a national survey. Acad Med. 2010;85(9):1537-42. https://doi.org/10.1097/ acm.0b013e3181eab71b

9. Mogre V, Stevens F, Aryee PA, Scherpbier AJJA. Nutrition in Medicine: Medical Students' Satisfaction, Perceived Relevance and Preparedness for Practice. Heal Prof Educ. 2018;4(1):31-8. https:// doi.org/10.1016/j.hpe.2017.02.003
10. Barros MB, Rodrigues BD, Porto LK, Ferreira IP, Botelho NM. Attitudes and Knowledge of Senior Medical Students regarding Clinical Nutrition. Rev bras educ méd. 2019;43(suppl 1):127-34. https://doi.org/10.1590/1981-5271v43suplemento1-20180250

11. Walker WA. Innovative teaching strategies for training physicians in clinical nutrition: an overview. J Nutr.

2003;133(2):541S-3S. https://doi.org/10.1093/jn/133.2.541s 